\title{
Evaluation of Laparoscopic Ventral Mesh Rectopexy in Complete Rectal Prolapse
}

\author{
AHMED M. NAFEI, M.D.; YASSER M. ABDELSAMEE, M.D. and MUSTAFA M. ABDO, M.Sc.
}

The Department of General Surgery, Faculty of Medicine, A in Shams University

\begin{abstract}
Background: Complete rectal prolapse is a condition that greatly impairs the quality of life. Treatment in adults is essentially surgical but the optimum method is still a challenging clinical problem in colorectal surgery. The literature offers abundant publications and there have been turns and twists in the evolution of surgical techniques for treatment of this condition.
\end{abstract}

Aim of Study: To evaluate the outcome of laparoscopic ventral mesh rectopexy as a procedure for repair of complete rectal prolapse in terms of recurrence rate and post-operative improvement of faecal incontinence and constipation. Perioperative outcomes, improvement in bowel dysfunction or appearance of new complications were documented from the hospital records maintained prospectively.

Patients and Methods: This was a retrospective cohort study conducted on 20 patients with complete rectal prolapse underwent laparoscopic ventral mesh rectopexy admitted from colo-rectal unit clinic of Ain Shams University hospital in the period from January 2017 to December 2018, were evaluated in the present study.

Results: Twenty patients 13 females $(65 \%)$ and 7 males (35\%) with median age of 47.7. Wexner constipation score improved significantly from the preoperative value of median (IQR) 6.5 (range, 2-19) to 6 (range, 2-12) ( $p$-value <0.001). In patients presenting with faecal incontinence (FI), significant improvement in post-operative wexner (Cleveland clinic incontinence score) (CCIS) from median (IQR) 14.5 (range $0-20)$ to 0 (range, $0-16)$ ( $p$-value $<0.001)$. Three cases $(15 \%)$ of complete rectal prolapse recurrence were reported within 18 months follow-up.

Conclusion: Despite a multitude of existing operative techniques for correction of rectal prolapse, we believe that laparoscopic ventral mesh rectopexy has obtained good results in terms of functional outcome of the abdominal procedures with low recurrence rate and significant improvement in constipation and faecal incontinence, offering the advantages of anterolateral mobilization, mesh repair and of a laparoscopic approach compared to an open one.

Key Words: Laparoscopic ventral mesh rectopexy - Complete rectal prolapse.

Correspondence to: Dr. Mustafa M. Abdo, E-Mail: Mustafa.abdoh21@gmail.com

\section{Introduction}

RECTAL prolapse, or procidentia is defined as a protrusion of the rectum beyond the anus. Complete or full-thickness rectal prolapse is the protrusion of whole the rectal wall through the anal canal. It is a condition that greatly impairs the quality of life. Treatment in adults is essentially surgical but the optimum method is still a challenging clinical problem in colorectal surgery. The literature offers abundant publications and there have been turns and twists in the evolution of surgical techniques for treatment of this condition [1].

Surgical approaches can be divided into perineal and abdominal approaches. In general, abdominal rectopexy is preferable to a perineal procedure, because of low long-term recurrence rates and superior correction of incontinence. However, it is widely known for poor resolution and frequent induction of new constipation. However higher recurrence rates after perineal procedures their advantage is that they avoid laparotomy, which makes them well suited for those of very poor risk or the very elderly patients expected to die before the prolapse is likely to recur [1]

The different techniques of abdominal rectopexy may involve rectopexy, with or without sigmoid resection, with ventral or posterior techniques, with the use of a mesh to fix the rectum to the sacrum or not. Finally, the mesh can be synthetic or biological and absorbable or non-absorbable [2]

If the ideal operation for rectal prolapse was designed from scratch, it would need to fulfil several essential criteria. It would be abdominal rather than perineal for best long-term cure of the prolapse, laparoscopic for lowest morbidity, and avoid the risks of an anastomosis. It would improve anorectal function and even have advantages for the middle compartment [1] . 
Laparoscopic ventral mesh rectopexy has been introduced as a novel minimally invasive development in the treatment of rectal prolapse. Many of the results achieved with this novel procedure are unsurprising and consistent with current best practice for rectal prolapse. In this sense though a limited anterior mobilization is a somewhat revolutionary technical step, the outcomes it produces are more evolutionary, building on the advantages of the current best approaches, whilst eliminating troublesome disadvantages [1].

Current evidence argues strongly for a routine laparoscopic approach to prolapse, allowing more elderly patients to be offered a definitive repair with the efficacy and functional advantages of an abdominal procedure, with the safety of a perineal one [1].

\section{Aim of the work:}

To evaluate the outcome of laparoscopic ventral mesh rectopexy as a procedure for repair of complete rectal prolapse in terms of recurrence rate and post-operative improvement of faecal incontinence and constipation.

\section{Patients and Methods}

Study design:

This was a retrospective cohort study conducted on 20 patients with complete rectal prolapse underwent laparoscopic ventral mesh rectopexy ad- mitted from colo-rectal unit clinic of Ain Shams University Hospital in the period from January 2017 to December 2018.

\section{Exclusion criteria:}

- Patients below 18 years old.

- Patients with recurrent rectal prolapse.

- Patients with complicated rectal prolapse.

- Patients with rectal prolapse associated with mass in rectum/sigmoid.

- Patients with obstructed defecation syndrome associated with redundant sigmoid.

- Patients classified III, IV, V according to ASA PS classification (American society of anesthesiologists physical status classification system).

\section{Patient evaluation:}

A comprehensive workup includes a detailed history, clinical assessment, contrast imaging and colonoscopy. It includes the duration of disease, past history of obstetric trauma in females and history of anal operations, symptoms such as constipation, faecal incontinence (FI), bleeding per rectum, per rectal and perineal examination in both left lateral and squatting position.

For constipation and faecal incontinence, Wexner constipation scoring system [3] and wexner (CCIS) [4] were used, respectively. Pre-operative constipation was defined as Wexner score $>5$, and pre-operative incontinence as CCIS $>5$.

Table (1): Wexner constipation Scoring System (Minimum Score, 0; Maximum Score, 30).

\begin{tabular}{|c|c|c|c|}
\hline Items & & ore & \\
\hline Frequency of bowel movements: & & me: Minutes in lavatory per attempt: & \\
\hline 1-2 times per $1-2$ days & 0 & Less than 5 & 0 \\
\hline 2 times per week & 1 & $5-10$ & 1 \\
\hline Once per week & 2 & $10-20$ & 2 \\
\hline Less than once per week 3 & 3 & $20-30$ & 3 \\
\hline Less than once per month 4 & 4 & More than 30 & 4 \\
\hline Difficulty: Painful evacuation effort: & & sistance: Type of assistance: & \\
\hline Never & 0 & & \\
\hline Rarely & 1 & Without assistance & 0 \\
\hline Sometimes & 2 & Stimulative laxatives & 1 \\
\hline Usually & 3 & Digital assistance or enema & 2 \\
\hline Always & 4 & & \\
\hline Completeness: Feeling incomplete evacuation: & & ilure: Unsuccessful attempts for evacuation per 24 hours: & \\
\hline Never & 0 & Never & 0 \\
\hline Rarely & 1 & $1-3$ & 1 \\
\hline Sometimes & 2 & $3-6$ & 2 \\
\hline Usually & 3 & $6-9$ & 3 \\
\hline Always & 4 & More than 9 & 4 \\
\hline Pain: Abdominal pain: & & story: Duration of constipation (years): & \\
\hline Never & 0 & 0 & 0 \\
\hline Rarely & 1 & $1-5$ & 1 \\
\hline Sometimes & 2 & $5-10$ & 2 \\
\hline Usually & 3 & $10-20$ & 3 \\
\hline Always & 4 & More than 20 & 4 \\
\hline
\end{tabular}


Table (2): Wexner continence (CCIS) Scoring System (Minimum Score, 0; Maximum Score, 20).

\begin{tabular}{lccccc}
\hline \multirow{2}{*}{$\begin{array}{l}\text { Type of } \\
\text { incontinence }\end{array}$} & \multicolumn{5}{c}{ Frequency } \\
\cline { 2 - 6 } & Never & Rarely & $\begin{array}{c}\text { Some- } \\
\text { times }\end{array}$ & Usually & Always \\
\hline Solid & 0 & 1 & 2 & 3 & 4 \\
Liquid & 0 & 1 & 2 & 3 & 4 \\
Gas & 0 & 1 & 2 & 3 & 4 \\
Wears pad & 0 & 1 & 2 & 3 & 4 \\
Lifestyle & 0 & 1 & 2 & 3 & 4 \\
$\quad$ alteration & & & & & \\
\hline
\end{tabular}

Never $=0$, Rarely $=1 /$ month, Usually $=1 /$ week, Always $=>1 /$ day .

\section{Pre-operatively:}

After full clinical evaluation and preoperative investigations, patients were scheduled for laparoscopic ventral mesh rectopexy. Patients underwent brief bowel preparation by rectal enemas and restriction to liquid diet 24 hours preoperatively. One gram of cefotaxime and 500mg of metronidazole were given intravenously at induction. Written informed consent was obtained from all patients. The Wexner continence (CCIS) and constipation scores were determined before and after surgery.

\section{Surgical technique:}

The original procedure was first described by D'Hoore et al. The rectosigmoid junction is retracted to the left and a peritoneal incision is made over the right side of the sacral promontory and extended in an inverted J-form along the rectum and over the deepest part of the pouch of Douglas. Special care is taken not to damage the right hypogastric nerve. Denonvillier's fascia is incised and the rectovaginal septum is broadly opened. No rectal mobilization or lateral dissection is performed. A strip of prolene mesh trimmed to $3.0 \times 17 \mathrm{~cm}$, is inserted. Using non-absorbable sutures, the mesh is sutured to the ventral aspect of the distal rectum and further fixed to the lateral seromuscular borders of the rectum proximal and distal to the incised pouch of Douglas. The mesh is fixed upon the sacral promontory using either sutures or an endofascia stapler. No traction is exerted on the rectum, which remains in the sacrococcygeal hollow. The lateral borders of the incised peritoneum are then closed over the mesh. No drain is left [5].

\section{Follow-up:}

During the next 2 weeks post operatively, laxatives are used along with instructions to avoid excessive straining at defection, thereafter the use of laxatives is determined according to the degree of recovery of bowel function. Follow-up was conducted at $3,6,12$, and 18 months post- operatively. During the visits of follow-up, the following parameters were evaluated: Improvement or persistence of symptoms of prolapse, recurrence and if present, is it a full thickness or a mucosal, changes in constipation and symptoms of difficult evacuation, changes in anal incontinence if it is present pre-operatively. Effect on sexual and urologic function, asking about: Impotence in males, dyspareunia in females \& symptoms of urinary tract infection, retrograde ejaculation in males, bladder dysfunction.

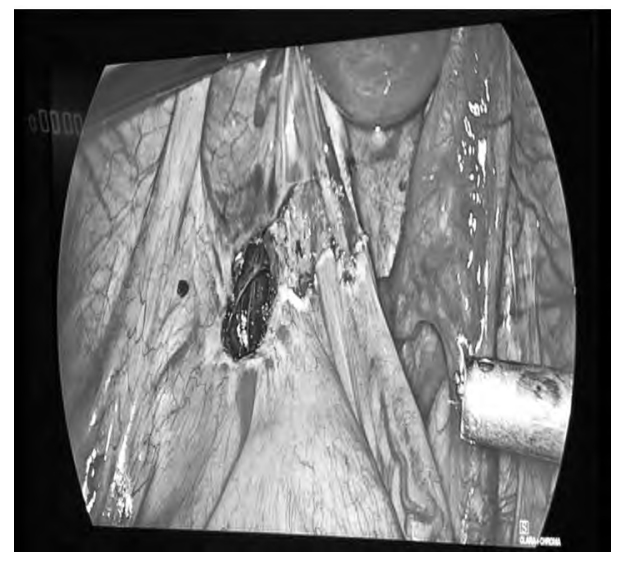

Fig. (1): Cranio-caudal retraction and dissection along the anterolateral aspect of the rectum (from our study).

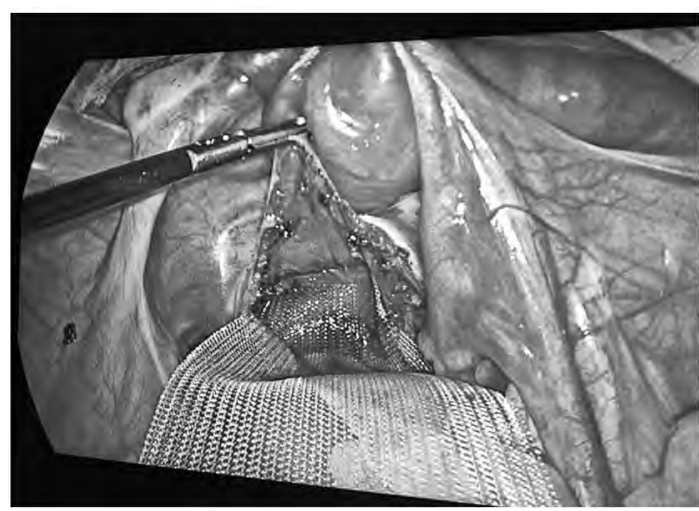

Fig. (2): Mesh insertion along the ventral aspect of the rectum (from our study).

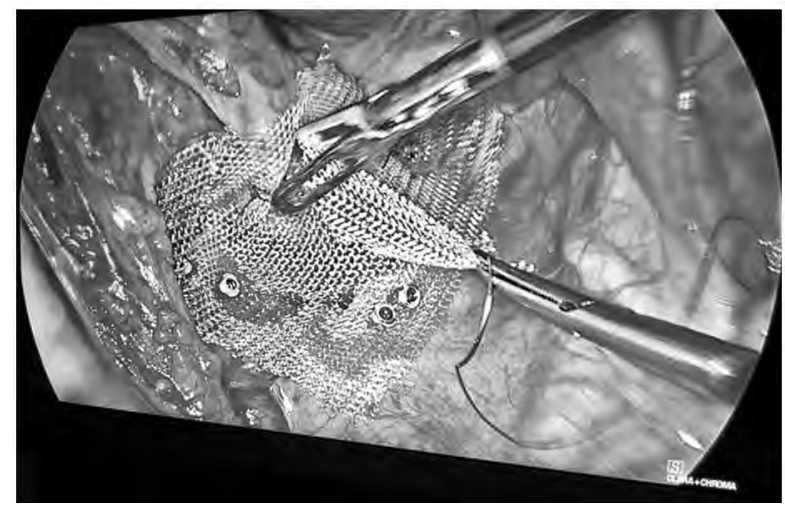

Fig. (3): Mesh fixation upon sacral promontry (from our study). 


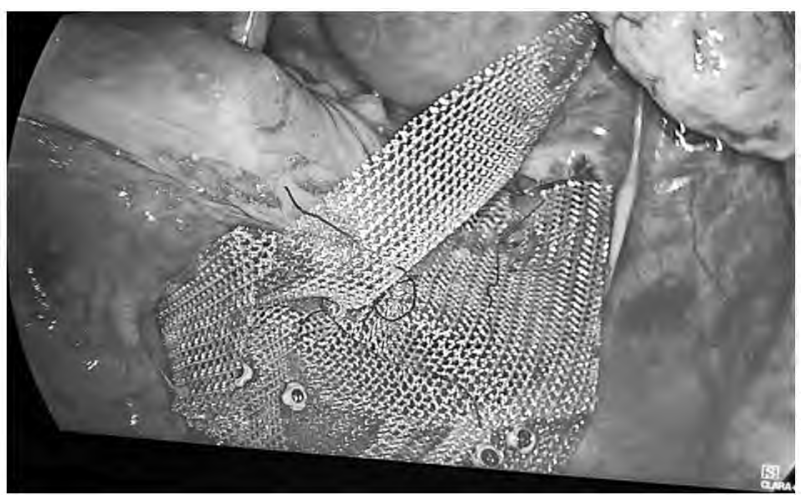

Fig. (4): Mesh is sutured to the ventral aspect and lateral seromuscular borders of the rectum using non-absorbable sutures (from our study).

\section{Results}

\section{Demographics and clinical characteristics:}

Twenty patients with complete rectal prolapse underwent laparoscopic ventral mesh rectopexy admitted from colo-rectal unit clinic of Ain Shams University Hospital in the period from January 2017 to December 2018, they were 13 females $(65 \%)$ and 7 males $(35 \%)$ with age ranged from 28 to 71 years. Associated symptoms were constipation $(65 \%)$ and faecal incontinence $(70 \%)$. The follow-up duration ranged from 9 to 18 months with a mean \pm SD of $17.55 \pm 2.01$.

\section{Functional outcomes:}

\section{Constipation:}

In those patients who had constipation at the time of presentation, there was a significant improvement in post operative Wexner score as compared to preoperative scores. Thirteen of 20 assessable patients $(65 \%)$ were constipated preoperatively. At 6 months post-operation, constipation was cured (7) or improved (3) in 10 out of these 13 patients (76.9\%) with a significant fall in the overall median preoperative Wexner score from 12 to 5.5. Constipation persisted in $3(23.1 \%)$ with no severe worsening or new onset of constipation.

\section{Faecal incontinence:}

No detrimental effect was noted in the six (30\%) continent patients. Before surgery, 14 (70\%) patients had some degree of incontinence. In all but $3(21.4 \%)$ the continence improved markedly. Seven of the 14 (50\%) incontinent patients became fully continent; 4 others $(28.6 \%)$ experienced only a minor degree of incontinence, with an incontinence score of less than 5. No patient experienced worsening or new-onset of faecal incontinence.

\section{Recurrence:}

Three patients (15\%) experienced recurrence of complete rectal prolapse within 18 months of follow-up.

\section{Discussion}

Complete rectal prolapse is a severely disabling condition that greatly impairs the quality of life. Surgery for prolapse not only aims to correct the anatomical defect but should also improve anorectal function and avoid post-operative functional sequelae That problem is addressed by several operative techniques and there is no worldwide consensus on which to use [7]

Abdominal rectopexy appears to be more effective than a perineal procedure in controlling prolapse also have an advantage of sufficient exposure not only of the rectum but other pelvic organs as well so used whenever feasible [5]. However, perineal procedures still remain a suitable option for a vast majority of elderly frail patients with multiple comorbidities who cannot withst and major abdominal surgery [6].

There have been turns and twists in the evolution of abdominal procedures and a large number of surgical techniques have been described in the literature. They all claim to cure the problem by restoring the anatomy and normalizing the physiology of the continence mechanism. But unfortunately, some approaches have even worsened the functional outcomes. Interference with the nerves, a loss of rectal compliance, and a slow transit constipation is a probable explanation of poor functional outcome especially after posterior and resectional rectopexies [6]

Minimal invasive surgery for rectal prolapse seems to be standard of care with advantage of less post operative pain, early return of bladder and bowel function, enhanced recovery, less incidence of adhesions and incisional hernia and small scars. Furthermore, laparoscopic rectal mobilization is likely to decrease blood loss in comparison with traditional open suture rectopexy [8] .

The primary endpoint was the incidence of recurrence of complete rectal during follow-up. Recurrence was defined as circumferential fullthickness protrusion of the rectum through the anal canal on straining. Secondary endpoints included improvement of incontinence and constipation.

Recurrence rates of prolapse after LVMR are generally low. Recurrence rate in our study is $15 \%$ of patients. A systematic review reported prolapse 
recurrence of $0 \%$ to $15 \%$ and mainly reflect differences in technique and length of follow-up [9], whereas a recent large series of 919 consecutive LVR patients by Consten et al., in 2015 reported their long-term recurrence rate of $8.2 \%$ [10].

Randall et al., studied 190 patients with rectal prolapse who underwent LVMR, and reported a recurrence rate of $3 \%$ which is lower than recurrences rate in our study. The reason of higher recurrence rate of LVMR in our study can be attributed to either technical factors or patientrelated factors [11]

De Bruijn et al. reported recurrence rate of complete rectal prolapse in $23 \%$ of patients at median follow-up of 5 years and explained this high recurrence rate as their study population had a median age of 66 years, which is slightly higher than in most studies [7].

The study by Fu et al., showed similar high recurrence of prolapse of $22.1 \%$ as they have taken a more liberal definition of recurrence to include other forms of posterior compartment prolapse, also $(29.6 \%)$ of patients who experienced recurrence had undergone prolapse repair operations, and lastly due to relatively longer median followup time in this study of about 4 years [12]

Long-term studies have shown that recurrence rates after complete rectal prolapse repair increase over the years [7]. Consten et al., showed Thirteen patients with complete rectal prolapse developed a clinical full thickness external prolapse recurrence generating a recurrence percentage (Kaplan-Meier estimates) of $4.2 \%, 7.2 \%$, and $8.2 \%$ after 3,5 , and 10 years respectively. Patients with recurrence may have an inherent tissue weakness, chronic pelvic floor laxity and poor anal sphincter function which contribute to recurrence [10]

A significant improvement in $(78.6 \%)$ of patients presented with FI was found in our study and can be explained by anatomical correction of the rectum as before surgery the rectum constantly presents to the anal canal which, by reflex, causes the internal sphincter muscle to relax. This type of incontinence often improves after surgery.

In the systematic review by Gouvas et al., six studies assessed the value of Ventral rectopexy for complete rectal prolapse reported pre- and postoperative incontinence in 191 patients which ranged from 23.3 to $92.9 \%$ and 0 to $28.6 \%$, respectively. Pooled analysis of the available data from all six studies demonstrated a statistically significant difference favouring the postoperative continence [9].
Slawik et al. showed improvement of incontinence in $(91 \%)$ of patients [13] . Collinson et al., also focused on improvement of incontinence and found significant reduction of incontinence in $85 \%$ of patients after a mean follow-up of 12 months [14].

It should be noted that these results are relatively short-term and the functional result may not be borne out over the longer term. Indeed our data indicate that the initial excellent improvement in faecal incontinence at 6 months. It remains to be seen whether there is a further tapering off of function over time. Nevertheless, many of these patients are elderly with relatively end-stage pelvic floors, and cannot be expected to be immune from deteriorating function in the longer term [1] .

In those patients who had constipation at the time of presentation, there was a significant improvement in post operative Wexner score as compared to pre-operative scores. At 6 months post operation, constipation was cured or markedly improved in $(76.9 \%)$ of these patients with a significant fall in the overall median preoperative Wexner score from 12 to 5.5. Constipation persisted in $(23.1 \%)$ with no severe worsening or new onset of constipation.

Similarly, in a series of 65 patients by Boons et al., constipation was cured or improved in (72\%) of constipated cohort with fall in the overall median preoperative Wexner score from 9 to 4 (1). Slawik et al reported improvement of symptoms of ODS in $(80 \%)$ of patients [13].

The cause of incontinence and constipation is regularly multifactorial and the patients who did not improve after surgery may have had other underlying factors causing symptoms of incontinence and constipation, such as anal sphincter failure or colonic transit disorders. Improved continence and constipation in patients after LVR seems to be caused by restored anatomy, probably resulting in a better function of the rectum, better sensitivity for faeces in the rectum and less bulging of the rectal wall, causing ODS [15]

In a prospective randomized study of rectopexy with and without resection, McKee et al., showed that patients with rectal prolapse who underwent abdominal rectopexy alone had a high incidence of constipation. They postulated that rectopexy leaves a redundant sigmoid colon that might kink over the fixed rectum and delay transit. The advantage of adding a resection to the rectopexy is a reduction in constipation. This procedure therefore seems suited to patients with a redundant sigmoid 
colon and a long history of constipation [16]. The major downsides of this popular technique are the risk of anastomotic leakage and the threat to continence with a colonic resection, especially in elderly patients [1]

D'Hoore et al., have postulated that postoperative constipation was prevented by the avoidance of posterolateral rectal mobilization, which interrupts the autonomic sympathetic innervation of the rectum, causing a hindgut 'denervation inertia' and distal slow transit. They reported that relief of symptoms of ODS in 16 of 19 (84\%) patients may be attributed to the ventral position of the mesh. The authors believe that resection rectopexy should be limited to selected patients with rectal prolapse and documented slow-transit constipation who have no major functional anal sphincter deficit [5]

\section{Conclusion:}

The principles of Laparoscopic ventral mesh rectopexy (LVMR) are limited anterior rectal mobilization avoiding the rectal autonomic nerve supply and support of the anterior rectal wall which performed through a minimally invasive technique. The ventral position of the prosthesis may explain the beneficial effect on symptoms of obstructed defecation and prevent post-operative worsening of constipation.

LVMR seems to be the feasible surgical procedure for complete rectal prolapse. It has the advantage of minimally invasive surgery with minimum morbidity and good functional outcomes in terms of significant improvement in constipation and faecal incontinence. Still, the evidence is lacking. Further larger prospective randomized control trials are needed to prove as a gold standard surgical technique.

\section{References}

1- BOONS P., COLLINSON R., CUNNINGHAM C. and LINDSEY I.: Laparoscopic ventral rectopexy for external rectal prolapse improves constipation and avoids de novo constipation. Colorectal Dis., 12 (6): 526-32, 2010.

2- PIGAZZI A.: Techniques in minimally invasive rectal surgery. Tech Minim Invasive Rectal Surg., 1-237, 2017.

3- AGACHAN F., CHEN T., PFEIFER J, REISSMAN P. and WEXNER S.D.: A constipation scoring system to simplify evaluation and management of constipated patients. Dis. Colon Rectum., 39 (6): 681-5, 1996.

4- JORGE J.M.N. and WEXNER S.D.: Etiology and management of fecal incontinence. Dis. Colon Rectum., 36 (1): 77-97, 1993.
5- D'HOORE A., CADONI R. and PENNINCKX F.: Longterm outcome of laparoscopic ventral rectopexy for total rectal prolapse. Br. J. Surg., 91 (11): 1500-5, 2004.

6- AHMAD N., STEFAN S., ADUKIA V., NAQVI S. and KHAN J.: Laparoscopic Ventral Mesh Rectopexy: Functional Outcomes after Surgery. Surg. J., 04 (04): e20511, 2018.

7- de BRUIJN H., MAEDA Y., TAN K.N., JENKINS J.T. and KENNEDY R.H.: Long-term outcome of laparoscopic rectopexy for full-thickness rectal prolapse. Tech Coloproctol [Internet], 23 (1): 25-31. Available from: http://dx.doi.org/10.1007/s10151-018-1913-z, 2019.

8- CHANDRA A., KUMAR S., MAURYA A.P., GUPTA V., GUPTA V. and RAHUL: Laparoscopic ventral mesh rectopexy for complete rectal prolapse: A retrospective study evaluating outcomes in North Indian population. World J. Gastrointest Surg., 8 (4): 321, 2016.

9- GOUVAS N., GEORGIOU P.A., AGALIANOS C., TAN E., TEKKIS P., DERVENIS C., et al.: Ventral colporectopexy for overt rectal prolapse and obstructed defaecation syndrome: A systematic review. Color Dis., 17 (2): O3446, 2015.

10- CONSTEN E.C.J., IERSEL Ã.J.J. VAN, VERHEIJEN Ã.P.M., BROEDERS I.A.M.J., WOLTHUIS Ã.A.M. and HOORE A.D.: 22 ND A NNUAL ESA M EETING Longterm Outcome After Laparoscopic Ventral Mesh Rectopexy An Observational Study of 919 Consecutive Patients, 2015.

11- RANDALL J., SMYTH E., McCARTHY K. and DIXON A.R.: Outcome of laparoscopic ventral mesh rectopexy for external rectal prolapse, (January 1997): 914-9, 2014.

12- STEVENSON A.R.L.: Risk Factors for Recurrence After Laparoscopic, 2: 178-86, 2017.

13- SLAWIK S., SOULSBY R., CARTER H., PAYNE H. and DIXON A.R.: Laparoscopic ventral rectopexy, posterior colporrhaphy and vaginal sacrocolpopexy for the treatment of recto-genital prolapse and mechanical outlet obstruction. Color Dis., 10 (2): 138-43, 2008.

14- COLLINSON R., WIJFFELS N., CUNNINGHAM C. and LINDSEY I.: Laparoscopic ventral rectopexy for internal rectal prolapse: Short-term functional results. Color Dis., 12 (2): 97-104, 2010.

15- FORMIJNE JONKERS H.A., POIERRIÉ N., DRAAISMA W.A., BROEDERS I.A.M.J. and CONSTEN E.C.J.: Laparoscopic ventral rectopexy for rectal prolapse and symptomatic rectocele: An analysis of 245 consecutive patients. Color Dis., 15 (6): 695-9, 2013.

16- E.L. M., C.P. D.: Surgical management of rectal prolapse. Nat Clin Pract Gastroenterol Hepatol [Internet], 4 (10): 552-61, 2007. Available from: http://www.embase.com/ search/results?subaction=viewrecord\&from $=$ export\&id $=\mathrm{L} 351032842 \% 5 \mathrm{Cnhttp}: / / \mathrm{dx}$.doi.org/10.1038/ncpgasthe p0952\%5Cnhttp://sfx.library.uu.nl/utrecht?sid=EMBAS E\&issn=17434378\&id=doi: 10.103 8\%2Fncpgasthep095 $2 \&$ atitle $=$ Surgical + management + of + rect 


\section{دراسة لتقييم نتائج إصلاح السقوط الشرجى الكلى

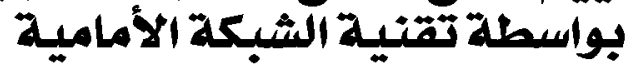 باستخدل ام المنظار الجراحيى}

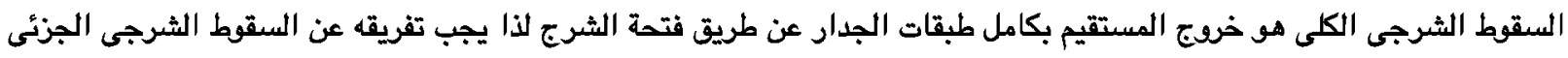

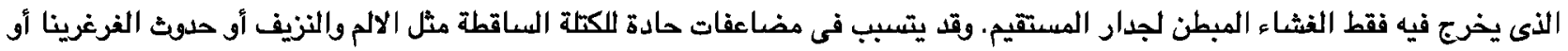

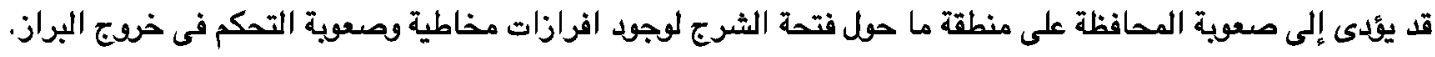

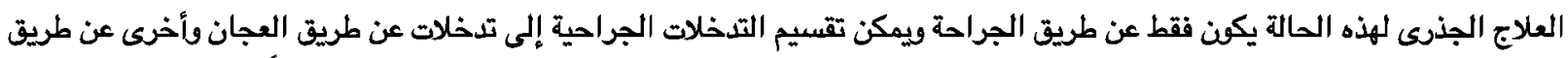

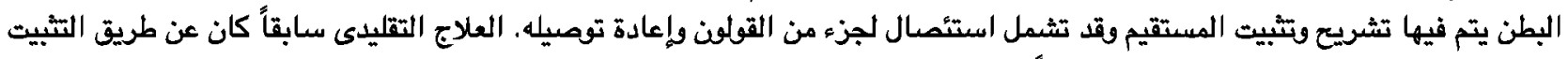

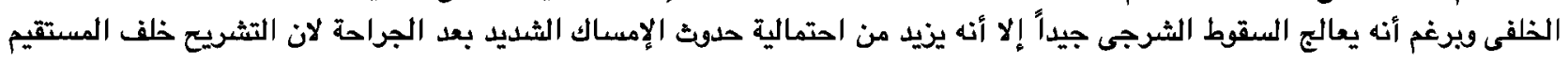
يؤدى إلى إصعابة التغذية العصبية المستقيم وحدوث الإئه الإمساك.

بالنظر لاستخدام المنظار ومقارنته بالاستكثاف الجراحى فى العلاج نجد أنه أفضل كثيراً من حيث تقليل شدة الألم وقصر مدة الإقامة

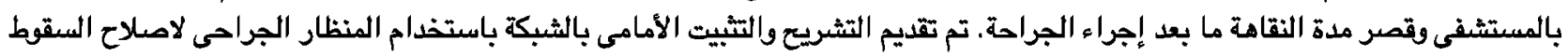

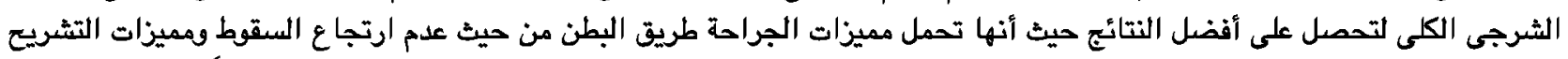

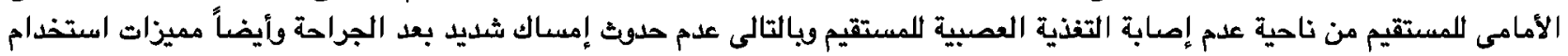

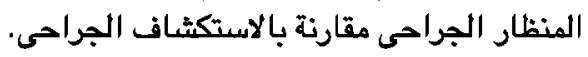

